\title{
Associations between serum vitamin D levels and precocious puberty in girls
}

\author{
Hae Sang Lee, MD, \\ You Jin Kim, MD, \\ Young Seok Shim, MD, \\ Hwal Rim Jeong, MD, \\ Eunbyul Kwon, MD, \\ Jin Soon Hwang, MD, PhD \\ Department of Pediatrics, \\ Ajou University Hospital, \\ Ajou University School of Medicine, \\ Suwon, Korea
}

\begin{abstract}
Purpose: Vitamin D deficiency has been linked to chronic diseases, such as diabetes mellitus, obesity and autoimmune disease. However, data on the vitamin D status and its association with precocious puberty in girls are limited. We aimed to investigate the association between serum 25-hydroxyvitamin D (25OHD) and precocious puberty in girls.

Methods: A total of 60 girls with central precocious puberty (CPP) and 30 control girls were enrolled. Anthropometric measurement and serum level of 25OHD were estimated for all subjects.

Results: There was a significant difference in the mean serum $250 H D$ concentration between the precocious puberty group and the control group $(17.1 \pm 4.5 \mathrm{ng} / \mathrm{mL}$ vs. $21.2 \pm 5.0 \mathrm{ng} / \mathrm{mL}, P<0.05)$. Forty-two of the 60 girls with CPP (70\%) had vitamin $D$ deficiency (defined as serum $250 \mathrm{HD}<20 \mathrm{ng} / \mathrm{mL}$ ) and $18(30 \%)$ had vitamin $D$ insufficiency. Of the 30 girls in the control group, vitamin D deficiency was seen in 13 subjects (43.3\%), 15 subjects (50\%) had vitamin D insufficiency, and 2 subjects (6.7\%) had sufficient serum vitamin $D$ (defined as serum $250 \mathrm{HD}>30 \mathrm{ng} / \mathrm{mL}$ ). Vitamin $\mathrm{D}$ deficient girls had a significantly higher odds ratio $(\mathrm{OR}, 3.05 ; 95 \% \mathrm{Cl}, 1.22-7.57$, $P=0.021$ ).

Conclusion: These results showed that vitamin $D$ levels may be associated with precocious puberty. Further studies are required to establish the potential effect of vitamin $D$ status on puberty.
\end{abstract}

Keywords: Vitamin D, Precocious puberty, Female
Received: 10 June, 2014

Revised: 24, June, 2014

Accepted: 30, June, 2014

Address for correspondence: Jin Soon Hwang, MD, PhD

Department of Pediatrics, Ajou

University School of Medicine,

206 World cup-ro, Yeongtong-gu,

Suwon 443-721, Korea

Tel: +82-31-219-5166

Fax: +82-31-219-5169

E-mail: pedhwang@ajou.ac.kr

\section{Introduction}

Vitamin D plays a crucial role in calcium and phosphorus metabolism throughout life. Main action of vitamin D includes intestinal calcium absorption and renal calcium reabsorption ${ }^{1)}$.

Mounting epidemiological studies have reported that vitamin D was associated with risk for many disorders, including certain types of cancer, neurologic disorders, infectious disease, cardiovascular disease, type 2 diabetes mellitus, and autoimmune disorders ${ }^{1,2)}$

Central precocious puberty (CPP) is characterized by early activation of the hypothalamicpituitary-gonadal axis before 8 years in girls and 9 years in boys ${ }^{3)}$. Recent studies reported that vitamin D status was associated with the timing of menarche ${ }^{4)}$ and vitamin D modulates reproductive function in women and $\mathrm{men}^{5,6)}$. However, there are no reports on the relationship between vitamin $\mathrm{D}$ levels and precocious puberty. The aim of this study was to determine the association of vitamin D status with CPP. This study compared the blood levels of vitamin D between girls with precocious puberty and girls with normal pubertal development.

\section{Materials and methods}

\section{Study population}


This cross-sectional study enrolled 60 girls with CPP (children and adolescents). Precocious puberty was defined according to the following criteria: objective breast budding appearing before 8 years of age, advanced bone age ( 1 year greater than the chronological age), and peak stimulated luteinizing hormone $(\mathrm{LH}) \geq 5.0 \mathrm{IU} / \mathrm{L}$ on immunoradiometric assay (IRMA) during gonadotropin-releasing hormone $(\mathrm{GnRH})$ stimulation $^{7)}$. To avoid seasonal variations, the study was undertaken at Ajou University Hospital, Suwon, Korea (latitude $37^{\circ}$ ), between April 2012 and June 2012. Exclusion criteria were precocious puberty with an identified etiology, such as brain tumor or cranial irradiation. Plasma 17-hydroxyprogesterone was measured to exclude abnormal androgen secretion. Serum thyroid function was measured to exclude hypothyroidism. Ovarian disorder was ruled out on the basis of pelvic ultrasound. We recruited 30 Korean girls with normal growth and development who had been followed at our pediatric growth clinic. Subjects taking medications known to affect the reproductive axis were also excluded and none of the study subjects had used hormonal medications before the study.

The study protocol was approved by the Ajou University Institutional Review Board and was in concordance with the Helsinki declaration. Written informed consent was obtained from the legal guardian of all the participants and the patient's consent was also obtained.

\section{Study design}

The serum 25-hydroxyvitamin D (25OHD) level of all the subjects was measured by radioimmunoassay. The GnRH stimulation test was performed at day time. Basal serum samples were obtained prior to GnRH injection (GnRH $100 \mu \mathrm{g} / \mathrm{m}^{2} \mathrm{IV}$ ), and post stimulation samples were acquired $30,45,60$, and 90 minutes after the injection for measurement of $\mathrm{LH}, \mathrm{FSH}$, and Estradiol $\left(\mathrm{E}_{2}\right)$ levels. The subjects' height, weight, pubertal status, thyroid function, and bone age were collected from the review of clinic charts and electronic medical records. Pubertal status (Tanner stage for breast development) was assessed and documented by one pediatric endocrinologist. Patients were categorized as being in the pubertal stage once they have reached Tanner 2-5) Bone age was measured using the method described by Greulich and Pyle ${ }^{8)}$. BMI was calculated and the BMI standard deviation scores (SDSs) were derived using the 2007 Korean National Growth Charts ${ }^{9)}$.

\section{Laboratory Measurements}

The detection limits for serum LH and FSH levels measured by IRMA (BioSource, Nivelles, Belgium) were $0.2 \mathrm{IU} / \mathrm{L}$ and $0.1 \mathrm{IU} / \mathrm{L}$, intra-assay coefficient of variation $(\mathrm{CV})$ ranging from $1.4 \%-3.9 \%$ and $1.1 \%-2.0 \%$, and inter-assay $\mathrm{CV}$ ranging from $3.4 \%-8.0 \%$ and $2.4 \%-4.4 \%$, respectively. $E_{2}$ levels were determined via radioimmunoassay with analytical sensitivity of $5 \mathrm{pg} / \mathrm{mL}$, intra-assay CV ranging from $4.0 \%-7.0 \%$, and inter-assay CV ranging from $4.2 \%-8.1 \%$ (radioimmunoassay;
Coat-A-Coung, Diagnostic Products, Los Angeles, CA, USA). Serum 25OHD concentration, as a marker of vitamin D status, was measured with a radioimmunoassay kit (DiaSorin Inc., Stillwater, MN, USA) using a gamma counter (1470Wizard, PerkinElmer, Turku, Finland). The following are the definitions of the various vitamin D states used in this study: sufficient vitamin D state, $25 \mathrm{OHD}$ of at least $75 \mathrm{nmol} / \mathrm{L}(30 \mathrm{ng} / \mathrm{mL})$; vitamin D insufficiency, less than $75 \mathrm{nmol} / \mathrm{L}(30 \mathrm{ng} / \mathrm{mL})$; and vitamin D deficiency, less than $50 \mathrm{nmol} / \mathrm{L}(20 \mathrm{ng} / \mathrm{mL})^{10)}$.

\section{Statistical analysis}

The clinical and laboratory parameters from the CPP and control groups were compared using the Student $t$-test. Subjects were divided into three subgroups according to their vitamin D status. The odds ratios (ORs) of precocious puberty depending on vitamin D levels were calculated by binary logistic regression. Statistical analysis was performed using IBM SPSS ver. 21.0 (IBM Co., Armonk, NY, USA). Statistical significance was defined as $P<0.05$. Results are described as mean \pm standard deviation (SD) unless otherwise stated.

\section{Results}

A total of 90 subjects participated in this study (CPP, 60; control subjects, 30 ). The mean age of the subjects was $8.09 \pm 0.94$ years. The mean $25 \mathrm{OHD}$ level was $18.5 \pm 5.0 \mathrm{ng} / \mathrm{mL}$. Most of the subjects $(97.7 \%)$ did not reach sufficient status. Assessment of pubertal status by the Tanner method in the CPP group showed that 35 girls were in Tanner stage 2, 20 girls in Tanner stage 3 , and 5 girls in Tanner stage 4. Clinical and laboratory characteristics of the CPP and control group are shown in Table 1. Mean 25OHD levels were significantly lower in children with precocious puberty $(17.1 \pm 4.5 \mathrm{ng} / \mathrm{mL}$ compared to $21.2 \pm 5.0$ $\mathrm{ng} / \mathrm{mL}$ ). In addition, children with CPP showed a significantly higher height SDS and weight SDS compared with the control group. There was no significant difference in BMI SDS between the CPP and control group.

Table 1. Clinical characteristics of girls with central precocious puberty and controls

\begin{tabular}{lccc}
\hline Characteristic & $\begin{array}{c}\text { Central precocious } \\
\text { puberty }(n=60)\end{array}$ & Control $(n=30)$ & $P$-value \\
\hline Age at onset $(y r)$ & $8.3 \pm 0.53$ & $7.6 \pm 1.3$ & 0.007 \\
Height SDS & $1.1 \pm 0.84$ & $-0.58 \pm 1.17$ & 0.001 \\
Weight SDS & $0.67 \pm 0.77$ & $-0.09 \pm 1.32$ & 0.001 \\
BMI SDS & $0.26 \pm 0.94$ & $-0.06 \pm 1.16$ & 0.185 \\
Bone age (yr) & $10.3 \pm 0.7$ & $7.5 \pm 1.58$ & 0.001 \\
BA-CA at diagnosis (yr) & $1.9 \pm 0.6$ & $-0.05 \pm 0.6$ & 0.001 \\
25OHD $(\mathrm{ng} / \mathrm{mL})$ & $17.15 \pm 4.55$ & $21.23 \pm 5.07$ & 0.001 \\
$1,25(\mathrm{OH})_{2} \mathrm{D}_{3}(\mathrm{ng} / \mathrm{mL})$ & $51.05 \pm 12.90$ & $54.17 \pm 21.40$ & 0.398 \\
\hline
\end{tabular}

Values are presented as mean \pm standard deviation.

SDS, standard deviation score; BMI, body mass index; BA-CA, bone age-chronological age; 25OHD, 25-hydroxyvitamin D; $1,25(\mathrm{OH})_{2} \mathrm{D}_{3}, 1,25$-dihydroxyvitamin D3. 
Subjects in the CPP group were further divided into two subgroups on the basis of the serum $25 \mathrm{OHD}$ values to compare the clinical characteristics and hormone values. The proportion of girls with advanced pubertal stage (Tanner 3 and 4) was higher in the vitamin $\mathrm{D}$ deficiency subgroup than in the vitamin D insufficiency subgroup, although there was no statistical significance $(P=0.052)$. No significant difference was seen in basal LH, peak LH, basal FSH, peak FSH, basal E2, peak E2 and bone age between the two subgroups (Table 2).

Table 3 compared the rates of CPP against the vitamin D status. Forty-two of the 60 girls with CPP (70\%) had vitamin D deficiency (defined as serum 25OHD $<20 \mathrm{ng} / \mathrm{mL}$ ) and $18(30 \%)$ had vitamin D insufficiency. Of the 30 subjects in the control group, vitamin D deficiency was seen in 13 subjects (43.3\%), 15 subjects (50\%) had vitamin D insufficiency, and 2 subjects (6.7\%) had sufficient vitamin $\mathrm{D}$ (defined as serum $25 \mathrm{OHD}>30 \mathrm{ng} / \mathrm{mL}$ ).

Table 2. Characteristics of study subjects with central precocious puberty according to $250 \mathrm{HD}$ status

\begin{tabular}{|c|c|c|c|}
\hline Characteristic & $\begin{array}{c}\text { Vitamin D } \\
\text { deficiency }(n=42)\end{array}$ & $\begin{array}{l}\text { Vitamin D } \\
\text { insufficiency } \\
(n=18)\end{array}$ & $P$-value ${ }^{a}$ \\
\hline Age (yr) & $8.3 \pm 0.46$ & $8.2 \pm 0.6$ & 0.383 \\
\hline Height SDS & $1.0 \pm 0.8$ & $1.1 \pm 0.9$ & 0.987 \\
\hline Weight SDS & $0.67 \pm 0.73$ & $0.67 \pm 0.88$ & 0.973 \\
\hline BMI SDS & $0.29 \pm 0.89$ & $0.19 \pm 1.06$ & 0.736 \\
\hline Tanner stage (breast) & & & $0.052^{b)}$ \\
\hline 2 & $21(50)$ & $14(77.8)$ & \\
\hline 3 & $16(38.1)$ & 4 (22.2) & \\
\hline 4 & $5(11.9)$ & - & \\
\hline Bone age (yr) & $10.3 \pm 0.7$ & $10.2 \pm 0.7$ & 0.669 \\
\hline BA-CA at diagnosis (yr) & $1.9 \pm 0.6$ & $2.0 \pm 0.8$ & 0.714 \\
\hline $25 \mathrm{OHD}(\mathrm{ng} / \mathrm{mL})$ & $14.92 \pm 3.42$ & $22.36 \pm 1.60$ & 0.001 \\
\hline $1,25(\mathrm{OH})_{2} \mathrm{D}_{3}(\mathrm{ng} / \mathrm{mL})$ & $51.08 \pm 14.12$ & $51.00 \pm 9.85$ & 0.982 \\
\hline Basal LH (IU/L) & $0.35 \pm 0.26$ & $0.40 \pm 0.45$ & 0.667 \\
\hline Basal FSH (IU/L) & $2.19 \pm 1.00$ & $2.27 \pm 1.30$ & 0.813 \\
\hline Basal E2 (pg/mL) & $6.73 \pm 2.97$ & $6.33 \pm 2.16$ & 0.559 \\
\hline Peak LH (IU/L) & $13.63 \pm 8.82$ & $12.05 \pm 8.12$ & 0.504 \\
\hline Peak FSH (IU/L) & $11.81 \pm 3.18$ & $13.25 \pm 4.20$ & 0.204 \\
\hline Peak E2 (pg/mL) & $7.85 \pm 3.38$ & $7.33 \pm 2.76$ & 0.534 \\
\hline
\end{tabular}

Values are presented as mean \pm standard deviation or number (\%). SDS, standard deviation score; BMI, body mass index; BA-CA, bone age-chronological age; 25OHD, 25-hydroxyvitamin $\mathrm{D} ; 1,25(\mathrm{OH})_{2} \mathrm{D}_{3}$, 1,25-dihydroxyvitamin D3; LH, luteinizing hormone; FSH, follicle stimulating hormone; E2, Estradiol.

${ }^{a}$ Independent $t$-test. ${ }^{\text {b) }}$ The proportion of Tanner stage was compared using the chi-square test depending on vitamin D status.
Vitamin D deficient girls had a significantly higher odds ratio (OR, 3.05; 95\% confidence interval [CI], 1.22-7.57; $P=0.021$ ). Also, the ORs of precocious puberty increased 1.19 fold in girls with decreased vitamin D levels in logistic regression analysis after adjusting weight SDS, BMI SDS, age (Table 4).

Pearson correlation coefficient analyses revealed no relationship between serum 25OHD and weight SDS $(r=-0.153$, $P=0.150)$, BMI SDS $(r=-0.086, P=0.418)$, peak LH $(r=-0.046$, $P=0.729)$, and peak E2 $(r=-0.099, P=0.450)$. However, a significant inverse correlation was found between $25 \mathrm{OHD}$ and the difference of bone age and chronological age $(r=-0.273$, $P=0.009$ ).

\section{Discussion}

Our study showed that the level of $25 \mathrm{OHD}$ was significantly lower in girls with CPP compared to those in normal control subjects. Among subjects in the precocious puberty group, $70 \%$ had deficiency in vitamin $\mathrm{D}$, compared to $43.3 \%$ from the group with normal pubertal development. Within the CPP group, advanced Tanner stage (Tanner stage 3 and 4) was more frequently observed in the vitamin D deficiency subgroup. Girls with CPP had higher risk of vitamin D deficiency (OR, 3.05 ; 95\% CI, 1.22-7.57). This is the first report examining the association between serum $25 \mathrm{OHD}$ levels and precocious puberty in girls.

Recently, many reports showed an increase in the incidence of CPP and a decline in age at pubertal onset in girls ${ }^{3,11}$. Although a lot of studies have reported on precocious puberty, the etiology underlying the early activation of the hypothalamicpituitary-gonadal axis is still unclear. Genetic factors are the major contributors in the timing of puberty ${ }^{12,13)}$. However, the observed secular trend in pubertal onset with a steady decline of the age at onset over the past decades clearly suggests that an environmental factor may be influencing the current change in pubertal progression ${ }^{14,15}$. In the last few years, the prevalence

Table 4. The multivariate analysis by logistic regression test to analyze the relationship between precocious puberty and vita$\min \mathrm{D}$

\begin{tabular}{lccc}
\hline & Odds ratio & 95\% Confidence interval & $P$-value \\
\hline $250 H D$ & 1.195 & $1.061-1.346$ & 0.003 \\
\hline
\end{tabular}

SDS, standard deviation score; BMI, body mass index; 25OHD, 25-hydroxyvitamin D.

${ }^{a}$ The binary logistic regression analysis after adjusting of weight SDS, BMI SDS, age.

Table 3. Prevalence of vitamin D deficiency in all subjects

\begin{tabular}{|c|c|c|c|c|c|}
\hline & Central precocious puberty & Control & Total & OR $(95 \% \mathrm{Cl})$ & $P$-value \\
\hline $250 \mathrm{OHD}(\mathrm{ng} / \mathrm{mL})$ & & & & $3.05(1.22-7.57)$ & 0.021 \\
\hline$<20$ & 42 & 13 & 55 & & \\
\hline$\geq 20$ & 18 & 17 & 35 & & \\
\hline Total & 60 & 30 & 90 & & \\
\hline
\end{tabular}

OR, odds ratio; $\mathrm{Cl}$, confidence interval; 25OHD, 25-hydroxyvitamin D.

${ }^{a)}$ Chi-square test. 
of vitamin $\mathrm{D}$ deficiency has been increasing in many parts of the world ${ }^{16)}$. Vitamin D plays a key role in bone metabolism, being important for the maintenance of calcium homeostasis by intestinal and renal calcium absorption ${ }^{2}$. The vast majority of the effects of vitamin $\mathrm{D}$ are mediated by the vitamin $\mathrm{D}$ receptor (VDR), which is the only protein that binds $1,25(\mathrm{OH})_{2} \mathrm{D}_{3}{ }^{17)}$. The VDR is expressed in almost all body cells, such as immune, vascular cells as well as ovary and human pituitary gland $^{18,19)}$. This has led to extensive research on vitamin $\mathrm{D}$ as a potential influencing factor in the pathogenesis of a number of nonskeletal diseases, including infectious and autoimmune diseases, obesity, cancer and fertility ${ }^{20)}$.

There are few studies looking at the association of vitamin $\mathrm{D}$ status and sexual maturation and female reproduction. The role of vitamin D deficiency on precocious puberty is not clear. In previous animal studies, vitamin D deficiency has lead to reduction in overall fertility of female rats compared to vitamin D-replete ones by direct regulation of aromatase gene expression $^{18,21)}$. In humans, the VDR gene polymorphism at the ApaI site is significantly associated with the earlier age at menarche ${ }^{22}$. In one study, age at menarche was earlier in girls living at higher geographic latitude than girls living towards the equator ${ }^{23)}$. Villamor et al. ${ }^{4)}$ followed a cohort of 242 healthy girls (age, 5-12 years) for a median of 30 months and found that vitamin $\mathrm{D}$ deficient girls have an earlier initiation of menstruation than girls with sufficient vitamin D. They explained that vitamin D deficiency was associated with obesity, so vitamin D status could indirectly affect the age at menarche by its effect on obesity. In our study, girls with CPP were also heavier than the normal control subjects, although the BMI SDS was not significantly differ between the two groups. The other possible mechanism was that vitamin $\mathrm{D}$ had inverse correlation with insulin-like growth factor-1 (IGF-1) ${ }^{24)}$. IGF- 1 modulates the onset of puberty and pubertal progression by stimulating the $\mathrm{GnRH}^{25}$. So, it is conceivable that vitamin D-mediated effects may influence IGF-1 levels and pubertal onset through an effect on gonadotropin and sex hormone.

This study has a few limitations stemming from relatively small sample size. The most subjects had vitamin D deficiency and insufficiency except two control girls. Also, we were unable to assess other hormones that affect the pubertal onset, such as IGF-1, as a result, causality cannot be proven.

In conclusion, our study indicated that vitamin D deficiency was more common in girls with CPP than girls with normal patterns of sexual maturation. Although the mechanism of vitamin D deficiency's effect on pubertal progression is unclear, we suggest that vitamin D may influence sexual maturation in girls. Further studies including more vitamin D sufficient subjects are required to establish the potential effect of vitamin D status on the development of puberty.

\section{Conflict of interest}

No potential conflict of interest relevant to this article was reported.

\section{References}

1. Wacker M, Holick MF. Vitamin D - effects on skeletal and extraskeletal health and the need for supplementation. Nutrients 2013;5:111-48.

2. Prentice A, Goldberg GR, Schoenmakers I. Vitamin D across the lifecycle: physiology and biomarkers. Am J Clin Nutr 2008;88:500S-506S.

3. Carel JC, Leger J. Clinical practice: precocious puberty. N Engl J Med 2008;358:2366-77.

4. Villamor E, Marin C, Mora-Plazas M, Baylin A. Vitamin D deficiency and age at menarche: a prospective study. Am J Clin Nutr 201 1;94:1020-5.

5. Yang B, Sun H, Wan Y, Wang H, Qin W, Yang L, et al. Associations between testosterone, bone mineral density, vitamin $\mathrm{D}$ and semen quality in fertile and infertile Chinese men. Int J Androl 2012;35:783-92.

6. Knight JA, Wong J, Blackmore KM, Raboud JM, Vieth R. Vitamin D association with estradiol and progesterone in young women. Cancer Causes Control 2010;21:479-83.

7. Neely EK, Wilson DM, Lee PA, Stene M, Hintz RL. Spontaneous serum gonadotropin concentrations in the evaluation of precocious puberty. J Pediatr 1995;127:47-52.

8. Greulich WW, Pyle SI. Radiologic atlas of skeletal development of the hand and wrist. 2nd ed. Standford: Stanford University Press, 1959.

9. Moon JS, Lee SY, Nam CM, Choi JM, Choe BK, Seo JW, et al. 2007 Korean National Growth Charts: review of developmental process and an outlook. Korean J Pediatr 2008;51:1-25.

10. Misra M, Pacaud D, Petryk A, Collett-Solberg PF, Kappy M; Drug and Therapeutics Committee of the Lawson Wilkins Pediatric Endocrine Society. Vitamin D deficiency in children and its management: review of current knowledge and recommendations. Pediatrics 2008;122:398-417.

11. Sorensen K, Mouritsen A, Aksglaede L, Hagen CP, Mogensen SS, Juul A. Recent secular trends in pubertal timing: implications for evaluation and diagnosis of precocious puberty. Horm Res Paediatr 2012;77:137-45.

12. Herbison AE. Genetics of puberty. Horm Res 2007;68 Suppl 5:75-9.

13. Seminara SB, Messager S, Chatzidaki EE, Thresher RR, Acierno JS Jr, Shagoury JK, et al. The GPR54 gene as a regulator of puberty. N Engl J Med 2003;349:1614-27.

14. Ahmed ML, Ong KK, Dunger DB. Childhood obesity and the timing of puberty. Trends Endocrinol Metab 2009;20:237-42.

15. Rasier G, Parent AS, Gerard A, Lebrethon MC, Bourguignon JP. Early maturation of gonadotropin-releasing hormone secretion and sexual precocity after exposure of 
infant female rats to estradiol or dichlorodiphenyltrichloro ethane. Biol Reprod 2007;77:734-42.

16. Prentice A. Vitamin D deficiency: a global perspective. Nutr Rev 2008;66(10 Suppl 2):S153-64.

17. Haussler MR, Jurutka PW, Mizwicki M, Norman AW. Vitamin D receptor (VDR)-mediated actions of $1 a, 25(\mathrm{OH})_{2}$ vitamin $\mathrm{D}_{3}$ : genomic and non-genomic mechanisms. Best Pract Res Clin Endocrinol Metab 2011;25:54359.

18. Kinuta K, Tanaka H, Moriwake T, Aya K, Kato S, Seino Y. Vitamin $\mathrm{D}$ is an important factor in estrogen biosynthesis of both female and male gonads. Endocrinology 2000;141:1317-24.

19. Perez-Fernandez R, Alonso M, Segura C, Munoz I, GarciaCaballero T, Diguez C. Vitamin D receptor gene expression in human pituitary gland. Life Sci 1997;60:35-42.

20. Abrams SA, Coss-Bu JA, Tiosano D. Vitamin D: effects on childhood health and disease. Nat Rev Endocrinol
2013;9:162-70.

21. Halloran BP, DeLuca HF. Effect of vitamin D deficiency on fertility and reproductive capacity in the female rat. J Nutr 1980;110:1573-80.

22. Kitagawa I, Kitagawa Y, Kawase Y, Nagaya T, Tokudome S. Advanced onset of menarche and higher bone mineral density depending on vitamin $\mathrm{D}$ receptor gene polymorphism. Eur J Endocrinol 1998;139:522-7.

23. Grivas TB, Vasiliadis E, Mouzakis V, Mihas C, Koufopoulos G. Association between adolescent idiopathic scoliosis prevalence and age at menarche in different geographic latitudes. Scoliosis 2006;1:9.

24. Breen ME, Laing EM, Hall DB, Hausman DB, Taylor RG, Isales CM, et al. 25-hydroxyvitamin D, insulin-like growth factor-I, and bone mineral accrual during growth. J Clin Endocrinol Metab 2011;96:E89-98.

25. DiVall SA, Radovick S. Pubertal development and menarche. Ann N Y Acad Sci 2008;1135:19-28. 